\title{
The Move Your Way Campaign: Encouraging Contemplators and Families to Meet the Recommendations From the Physical Activity Guidelines for Americans
}

\author{
Frances Bevington, Katrina L. Piercy, Kate Olscamp, Sandra W. Hilfiker, \\ Dena G. Fisher, and Elizabeth Y. Barnett
}

\begin{abstract}
Background: The Move Your Way campaign, developed by the Office of Disease Prevention and Health Promotion, aims to improve Americans' adherence to the Physical Activity Guidelines for Americans. This article describes the research that informed the campaign's products, messaging, and strategy. Methods: A mixed-methods approach was used to understand participants' preferences for physical activity messages and information seeking. Two rounds (round 1 [ $\mathrm{n}=95]$ and round $2[\mathrm{n}=73])$ of focus groups and an online survey $(\mathrm{n}=2050)$ were conducted with adult physical activity contemplators. A third round $(n=84)$ of focus groups was conducted with children, teens, and parents of young children. Results: Adults, parents, teens, and children preferred messages that reflected diverse examples of activities; most participants disliked "one-sizefits-all" recommendations. Adults and parents preferred messages that emphasized specific health benefits over generic messages about overall health. Although some participants preferred getting physical activity information from digital search tools and social media platforms, many preferred getting this information from family members and friends. Conclusion: The Office of Disease Prevention and Health Promotion translated these findings into 3 themes used for Move Your Way implementation: (1) leverage social and community connections, (2) emphasize representation through inclusion and diversity, and (3) customize physical activity recommendations to make them more achievable.
\end{abstract}

Keywords: exercise, national, communication, health behavior

Physical activity has been described as a wonder drug-a lowcost, accessible solution with the ability to impact many chronic health conditions and health outcomes. Regular physical activity influences all-cause mortality, brain health, risk of falls, bone health, weight status, and conditions such as coronary heart disease, cancer, type 2 diabetes, and hypertension. ${ }^{1}$ Yet despite these health benefits, most Americans do not engage in the recommended amounts of physical activity each week. Only $26 \%$ of men, $19 \%$ of women, ${ }^{2}$ and $20 \%$ of teens ${ }^{1}$ report activity levels sufficient to meet the relevant aerobic and muscle-strengthening guidelines. Increasing physical activity among the American population will require interventions across sectors at the individual, group, and community levels. ${ }^{1}$ Evidence shows that health promotion communication campaigns can effectively facilitate behavior change. ${ }^{3,4}$ Further, as the 2018 Physical Activity Guidelines Advisory Committee concluded in its Scientific Report, "Strong evidence shows that behavior change theories and techniques are effective for increasing physical activity levels." 3 In an effort to increase the number of Americans working toward and meeting the Physical Activity Guidelines for Americans, the Office of Disease Prevention and Health Promotion (ODPHP) developed the Move Your Way campaign. Move Your Way is a multichannel, community-based communication campaign that provides print and online resources for consumers and health care providers. The campaign is grounded in the transtheoretical model of behavior change and aims to impact the behavior of physical activity contemplators. $^{5}$

Bevington, Piercy, and Olscamp are with the U.S. Department of Health and Human Services, Office of Disease Prevention and Health Promotion, Rockville, MD, USA. Hilfiker, Fisher, and Barnett are with CommunicateHealth, Inc, Rockville, MD, USA. Barnett (lizzie@ communicatehealth.com) is corresponding author.
The transtheoretical model has been used as the foundation for interventions to promote healthy behaviors, such as smoking cessation, condom use, cancer screenings, and physical activity. ${ }^{6-8} \mathrm{Com}-$ munication interventions grounded in the transtheoretical model often tailor messages specific to stages of change, in an effort to stimulate behavior change. Rather than attempt to create a single message for Americans across the activity spectrum, ODPHP aimed to deliver messages that were specifically relevant to physical activity contemplators. Contemplators are defined as individuals who are not currently meeting the guidelines, but who are thinking about starting to become physically active within the next 6 months. ${ }^{9}$ Evidence shows that inactive people can gain substantial health benefits by increasing their physical activity even if they do not reach the target range. ${ }^{1}$ The steep slope at the lower bounds of physical activity and mortality and disease curves indicates that individuals can begin accruing health benefits through any reduction in sedentary behavior or increase in moderate to vigorous physical activity. ${ }^{1}$ By targeting physical activity contemplators, and aiming to increase their knowledge, self-efficacy, and, ultimately, their physical activity behavior, the Move Your Way campaign has the potential to significantly impact health status at the population level.

To support the development of the Move Your Way campaign, ODPHP employed a mixed-methods research approach that included focus groups and an online survey to better understand how socioeconomic factors, disability, barriers and motivators, and preferences could be related to the knowledge, awareness, and behavior of physical activity contemplators. Since parental role modeling has been positively associated with physical activity in children, ${ }^{10}$ ODPHP also sought to understand factors influencing parents (as a subset of physical activity contemplators), as well as their children, in order to inform messages, tools, and resources that would help 
parents add physical activity to family leisure-time recreational activities. Because attributes of the physical environment appear to moderate the effect of physical activity mass media interventions, ${ }^{11}$ ODPHP aimed to better understand how place-based messages and strategies could be utilized through the Move Your Way campaign.

This article summarizes findings related to 2 key research questions about preferences that shaped the development of the campaign: (1) What are message preferences among physical activity contemplators, parents, children, and teens? and (2) What are preferences among physical activity contemplators, parents, children, and teens for seeking information about physical activity? The accompanying article, "Understanding contemplators' knowledge and awareness of the Physical Activity Guidelines," 12 appearing in this issue, summarizes survey findings related to contemplators' awareness of the Guidelines, knowledge of physical activity, and knowledge of dosage recommendations.

\section{Methods}

To answer the 2 key research questions, ODPHP worked with a health education and communication firm to conduct audience research with consumers. The overarching goal was to use the findings to inform the development of a campaign and icon that would translate recommendations from the guidelines into accessible, actionable messages intended to move physical activity contemplators to the preparation and action stages. ODPHP used a mixed-methods approach that included 3 rounds of focus groups $(n=252)$ and an online survey of adults $(n=2050)$. Studies were reviewed for compliance with the Paperwork Reduction Act and approved by the Chesapeake IRB (now Advarra) Review Board.

\section{Recruitment and Eligibility}

Research was targeted to communities in 4 states that are among those with the highest percentages of adults who report no leisuretime physical activity within the United States: Baltimore, MD; Chicago, IL; Jackson, MS; and Las Vegas, NV. ${ }^{13}$ These locations were also chosen for regional diversity. ${ }^{14}$ Only participants who were identified as physical activity contemplators (based on their answers to questions about their physical activity behavior and intention) and reported infrequent physical activity were eligible to be included in the study. Activity level was determined through screening questions that asked about frequency and duration of physical activity (eg, "How often do you get physical activity for at least 20 minutes a day?").

For round 1 and round 2 focus groups, English- and Spanish-speaking adults and parents of children aged 12-17 years were recruited by a professional recruitment company. Selection criteria were provided to a professional recruitment firm, which used contacts in their own database to identify and select potential participants. Adult participants were eligible to participate if they reported (1) infrequent physical activity and (2) the intention to increase physical activity in the next 6 months. Parents of children aged 12-17 years were eligible to participate if they met all of the above criteria for adults and reported (1) infrequent physical activity for at least one of their children aged between 12 and 17 years and (2) that they plan to encourage their child to be more physically active in the next 6 months.

For round 3 focus groups, English-speaking children aged 8-12 years, teens aged 13-16 years, and parents of children aged 3-6 years were recruited by a professional recruitment company. Selection criteria were provided to the company, which used contacts in their own database to identify and select potential participants. Children and teens were eligible to participate if their parent or guardian reported infrequent physical activity for that child or teen. Parents of children aged 3-6 years were eligible to participate if they reported (1) infrequent physical activity for themselves, (2) infrequent physical activity for at least one of their children aged 3-6 years, and (3) that their child needs a parent or someone else to motivate them to be physically active at least occasionally.

For the survey, English-speaking adults aged 25-74 years were recruited by a Qualtrics (Provo, UT) online survey panel. Qualtrics, a market research company, identifies respondents for online surveys through an actively managed panel of members. Qualtrics recruits panel members through various channels, including social media, websites, and through collaboration with its global partners. People in the pool of respondents have previously agreed to be contacted by market research services that seek survey respondents. Because of the lower number of respondents available in Jackson and Las Vegas, recruitment in those areas was expanded to include the entire states of Mississippi and Nevada. Participant quotas were established for area (urban/suburban/rural), sex, race/ ethnicity, education, income, and disability to ensure that results reflected a demographically diverse sample. Eligible participants who completed the survey received Qualtrics reward points (worth less than \$5). Participants were eligible to participate if they reported (1) infrequent physical activity and (2) the intention to increase physical activity in the next 6 months.

Participants' age varied depending on method as described in Table 1. Research methods are described in chronological order. A complete breakdown of survey and focus group and participants by audience category is provided in Table 1 .

\section{Table 1 Participants by Audience Category and Research Activity}

\begin{tabular}{|c|c|c|c|c|}
\hline Audience category & $\begin{array}{l}\text { Focus groups, round } 1 \\
\text { (English and Spanish) }\end{array}$ & $\begin{array}{l}\text { Online survey } \\
\text { (English) }\end{array}$ & $\begin{array}{l}\text { Focus groups, round } 2 \\
\text { (English and Spanish) }\end{array}$ & $\begin{array}{c}\text { Focus groups, round } 3 \\
\text { (English) }\end{array}$ \\
\hline Children aged 8-12 y & N/A & N/A & N/A & 25 \\
\hline Teens aged $13-16$ y & N/A & N/A & N/A & 31 \\
\hline Parents of children aged $3-6 y^{a}$ & N/A & N/A & N/A & 28 \\
\hline Parents of children/teens aged $12-17 \mathrm{y}^{\mathrm{b}}$ & 47 & 378 & 33 & N/A \\
\hline Adults ${ }^{c}$ & 48 & 1672 & 40 & N/A \\
\hline Total & 95 & 2050 & 73 & 84 \\
\hline
\end{tabular}

Abbreviation: N/A, not applicable.

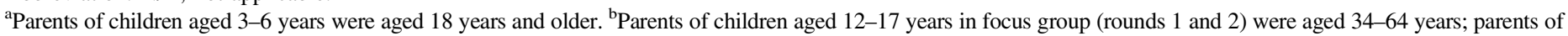

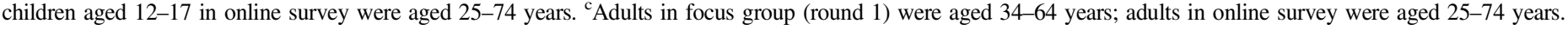




\section{Focus Groups, Round 1: Formative Research With Adults and Parents of Teens}

The 12 focus groups in the initial round were conducted in both English and Spanish in February 2017 with adult physical activity contemplators $(n=95)$. Participants were asked a series of questions intended to gauge their awareness and understanding of existing federal physical activity guidance, as well as questions intended to identify barriers and motivators to physical activity and preferences for receiving information about physical activity. Four of the 12 focus groups were conducted with those who answered screening questions that identified them as parents of teens. These participants were asked an additional series of questions pertaining to the physical activity behaviors, barriers, motivators, and preferences of their teenage children. Participants' responses were reviewed for common themes and topics and analyzed for differences that could be related to geographic location and parental status. Findings from this initial round of focus groups were used to inform questions for the online survey.

\section{Online Survey: Formative Research With Adults and Parents of Teens}

An online survey was conducted in May to June 2017 with Englishspeaking adults $(n=2050)$. The survey was intended to provide quantitative support to findings discovered through the initial focus groups. Questions were grouped into categories to assess demographic characteristics, physical activity behaviors and goals, physical activity barriers and facilitators, preferences for communication channels, and preferences for mobile health tools and technologies. Data collected through the survey were analyzed using univariate and bivariate statistical analyses to describe sample demographics and aggregate responses to measured constructs. Differences in the data based on demographic or categorical outcomes were analyzed using Pearson chi-square tests and Fisher exact tests when appropriate. The findings from the survey and the initial round of focus groups were used to inform prototype images, messages, and resources that were further tested and refined during subsequent rounds of focus groups.

\section{Focus Groups, Round 2: Message Testing With Adults and Parents of Teens}

The second round of 9 focus groups was conducted in both English and Spanish in October 2017 with adult physical activity contemplators $(n=73)$. Four of these focus groups were conducted with parents of teens. This round of focus groups was intended to test prototype messaging and imagery based on themes and preferences discovered in the initial round of focus groups and the online survey. Participants were asked to respond to prototype messages by identifying themes, phrases, and words that they found motivating or demotivating. Participants' responses were analyzed to identify motivating themes and messages as well as differences that could be related to geographic location and parental status. Findings from the focus groups were used to further refine messages and imagery.

\section{Focus Groups, Round 3: Message Testing With Children Aged 8-12 Years, Teens, and Parents of Children Aged 3-6 Years}

The third round of 12 focus groups was conducted in February 2018 with specific English-speaking audiences to examine how messages and preferences informed by the first 2 rounds of focus groups translated to additional audiences. The focus groups consisted of four 60 -minute sessions with children aged 8-12 years $(n=25)$, four 60-minute sessions with teens aged 13-16 years $(n=31)$, and four 90-minute sessions with parents of young children aged 3-6 years $(n=28)$. As with previous focus groups, participants were asked to identify barriers and facilitators, as well as messages that they found motivating. Participants' responses were reviewed for common themes and preferences and analyzed for differences that could be related to geographic location.

\section{Results}

Overall, ODPHP collected information about message preferences and physical activity information-seeking preferences from 2302 participants aged from 8 to 74 years. Of these participants, 49 were Spanish speaking. Although adult and parent participants were recruited to reflect diversity in sex, race, income, and education, the online survey included higher proportions of participants who were female and white, had middle to high income ranges, and held 4-year college degrees, as reflected in Table 2. Adult focus group participants were more proportionately distributed across demographic categories, as described in Table 2.

\section{Research Question 1: What Are Message Preferences Among Physical Activity Contemplators, Parents, Children, and Teens?}

To answer this question, findings from all 4 research activities summarized in the "Methods" section were considered. Because each subsequent research activity was built upon findings from previous research activities, findings tended to be reinforced, as more was learned about the various audiences. Findings supported by more than one activity were considered strong and are outlined in Table 3. Of these findings, 3 were particularly strong. First, participants preferred messages that reflected their diverse views about what qualifies as physical activity. This finding appeared in all 4 research activities for all types of participants (adults, parents, children, and teens). Second, the finding that adults and parents preferred messages emphasizing the short- and long-term benefits of physical activity was found across 3 research activities. Notably, adults and parents preferred specific messages about health benefits that were related to disease management for conditions like high blood pressure and type 2 diabetes, as well as messages about short-term benefits related to improved sleep and mood over generic messages about overall health (eg, "physical activity is good for your health"). Finally, a finding that stretched across 3 audiences (parents, kids, and teens) was that these participants reported liking messages that describe how physical activity can improve sleep, help them manage stress, and improve school performance.

\section{Research Question 2: What Are Preferences Among Physical Activity Contemplators, Parents, Children, and Teens for Seeking Information About Physical Activity?}

To answer this question, findings from 3 research activities were considered: round 1 of the focus groups, the online survey, and round 3 of the focus groups. Round 2 of the focus groups concentrated primarily on message testing and did not include 
Table 2 Adult and Parent Participants by Demographic Characteristics and Research Activity

\begin{tabular}{|c|c|c|c|c|}
\hline $\begin{array}{l}\text { Demographic } \\
\text { characteristics }\end{array}$ & $\begin{array}{l}\text { Focus groups, round } 1 \\
(n=95), \%\end{array}$ & $\begin{array}{c}\text { Online survey } \\
(n=2050), \%\end{array}$ & $\begin{array}{c}\text { Focus groups, round } 2 \\
(n=73), \%\end{array}$ & $\begin{array}{c}\text { Focus groups, round } 3 \\
(n=28), \%\end{array}$ \\
\hline \multicolumn{5}{|l|}{ Sex } \\
\hline Male & 44 & 29 & 48 & 57 \\
\hline Female & 57 & 71 & 52 & 43 \\
\hline \multicolumn{5}{|l|}{ Race } \\
\hline White & 36 & 74 & 45 & 46 \\
\hline Hispanic/Latino & 36 & 6 & 36 & 14 \\
\hline Black/African American & 26 & 13 & 15 & 32 \\
\hline Other & 3 & 7 & 4 & 7 \\
\hline \multicolumn{5}{|l|}{ Income } \\
\hline Less than $\$ 20,000$ & 8 & 11 & 3 & 7 \\
\hline$\$ 20,000-\$ 34,999$ & 22 & 13 & 23 & 18 \\
\hline$\$ 35,000-\$ 49,999$ & 33 & 15 & 22 & 29 \\
\hline$\$ 50,000-\$ 74,999$ & 18 & 23 & 26 & 18 \\
\hline$\$ 75,000-\$ 99,999$ & 7 & 16 & 15 & 14 \\
\hline$\$ 100,000$ or more & 13 & 24 & 11 & 14 \\
\hline \multicolumn{5}{|l|}{ Education level } \\
\hline High school or less & 26 & 15 & 23 & 7 \\
\hline $\begin{array}{l}\text { Some college, technical school, } \\
\text { or associate degree }\end{array}$ & 32 & 36 & 44 & 54 \\
\hline 4-y college or more & 42 & 49 & 33 & 36 \\
\hline
\end{tabular}

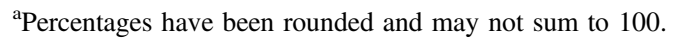

Table 3 Physical Activity Message Preferences

\begin{tabular}{|c|c|c|c|c|}
\hline Finding & $\begin{array}{c}\text { Focus groups, } \\
\text { round } 1\end{array}$ & $\begin{array}{l}\text { Online } \\
\text { survey }\end{array}$ & $\begin{array}{c}\text { Focus groups, } \\
\text { round } 2\end{array}$ & $\begin{array}{c}\text { Focus groups, } \\
\text { round } 3\end{array}$ \\
\hline $\begin{array}{l}\text { All participant groups reported diverse views about what qualifies as } \\
\text { physical activity and reported a preference for messages that } \\
\text { reflected diverse and inclusive examples of activities. }\end{array}$ & $x$ & $x$ & $\times$ & $x$ \\
\hline $\begin{array}{l}\text { Adults and parents reported liking messages that emphasized } \\
\text { short- and long-term health benefits from physical activity. }\end{array}$ & $x$ & & $\times$ & $x$ \\
\hline $\begin{array}{l}\text { Adults and parents reported that they preferred messages about } \\
\text { setting realistic goals and criticized "one-size-fits-all" physical } \\
\text { activity recommendations. }\end{array}$ & $x$ & & $\times$ & \\
\hline $\begin{array}{l}\text { Adults and parents reported wanting messages about how to do } \\
\text { different types of physical activity at home or in the office and how } \\
\text { to fit physical activity into their daily routines. }\end{array}$ & & $\times$ & $\times$ & \\
\hline $\begin{array}{l}\text { Parents, kids, and teens reported liking messages that describe how } \\
\text { physical activity can improve sleep, help them manage stress, and } \\
\text { improve school performance. }\end{array}$ & & & $x$ & $\times$ \\
\hline $\begin{array}{l}\text { Parents reported disliking messages that they perceived to be } \\
\text { judgmental, such as tips that suggest that their current choices are } \\
\text { undesirable (eg, instead of going to a restaurant, try a family picnic). }\end{array}$ & & & $x$ & $x$ \\
\hline $\begin{array}{l}\text { Parents reported liking messages that emphasized their role in } \\
\text { promoting healthy habits for life with their children. }\end{array}$ & & & $\times$ & $\times$ \\
\hline
\end{tabular}

questions about preferences for message source. Therefore, findings from round 2 were not considered for this research question. Because each subsequent research activity built upon findings from previous research activities, findings tended to be reinforced as more was learned about the audiences. Findings supported by more than one activity were considered strong and are outlined in Table 4. Many of the findings were supported by all 3 activities, and preferences for seeking information about physical activity tended to align with preferences for seeking information about health (eg, doctors and medical professionals were identified as sources of both health information and information about physical activity). Some information-seeking preferences identified were popular digital search tools (eg, Google) and social media platforms (eg, Facebook and YouTube). Further, some findings provided 
Table 4 Physical Activity Information-Seeking Preferences

\begin{tabular}{|c|c|c|c|}
\hline Finding & $\begin{array}{l}\text { Focus groups, } \\
\text { round } 1\end{array}$ & $\begin{array}{l}\text { Online } \\
\text { survey }\end{array}$ & $\begin{array}{l}\text { Focus groups, } \\
\text { round } 3\end{array}$ \\
\hline $\begin{array}{l}\text { Adults and teens rarely sought out physical activity guidance for themselves. Parents rarely } \\
\text { sought guidance for themselves or for their children. }\end{array}$ & $\times$ & $\times$ & $\times$ \\
\hline $\begin{array}{l}\text { Adults, parents, and kids identified YouTube videos as a source for health information and } \\
\text { physical activity information. }\end{array}$ & $\times$ & $\times$ & $\times$ \\
\hline $\begin{array}{l}\text { Adults and parents reported that they use online searches (eg, Google) when seeking health } \\
\text { information and physical activity information. }\end{array}$ & $\times$ & $\times$ & $\times$ \\
\hline $\begin{array}{l}\text { Adults and parents identified doctors and medical professionals as sources for health information } \\
\text { and physical activity information. }\end{array}$ & $\times$ & $\times$ & $\times$ \\
\hline $\begin{array}{l}\text { Parents, kids, and teens identified teachers and schools as sources of health information but not } \\
\text { necessarily physical activity information. }\end{array}$ & $\times$ & $\times$ & $\times$ \\
\hline Adults and parents primarily identified Facebook as their social media platform of choice. & $\times$ & $\times$ & $x$ \\
\hline Adults, parents, and children associated physical activity with nutrition. & $\times$ & & $\times$ \\
\hline $\begin{array}{l}\text { Adults and parents identified family and friends as preferred sources for health and physical } \\
\text { activity information. }\end{array}$ & $\times$ & $\times$ & \\
\hline $\begin{array}{l}\text { Adults, parents, and teens reported a preference for social media as the most popular source for } \\
\text { digital health and physical activity information. }\end{array}$ & & $x$ & $\times$ \\
\hline
\end{tabular}

insight into preferences specific to seeking information about physical activity, rather than preferences for seeking other health information or for particular digital sources. Specifically, adults and teens were not deliberately seeking out physical activity guidance, and parents were not seeking guidance for themselves or for their children. Further, adults, parents, and children tended to think of physical activity information in relation to, or alongside, nutrition information. Parents, children, and teens also noted that they typically receive information about health and nutrition from teachers and schools, but specifically said they do not receive physical activity information from those sources. Adults, parents, and teens also preferred community-based sources, such as family and friends, for physical activity information over other sources, such as digital media (eg, online searches and social media) and traditional media (eg, television, newspapers, and radio).

\section{Discussion}

The research summarized in this manuscript is unique because it looks specifically at physical activity message preferences and physical activity information-seeking preferences among physical activity contemplators. Further, this study sought to understand preferences among different age groups and how these preferences could impact the development of messages and strategies intended to encourage families to get more active together. Although some findings reinforced what is known about information-seeking preferences related to health among the general population, many findings seem specific to physical activity. ODPHP translated the findings summarized in this manuscript into 3 overarching themes for physical activity messages and information delivery strategies: (1) leverage social and community connections, (2) emphasize representation through inclusion and diversity, and (3) customize physical activity recommendations to make them more achievable.

\section{Leverage Social and Community Connections}

ODPHP concluded that many contemplators likely prefer to receive physical activity messages from community sources (eg, community leaders, friends, family, and health professionals). Therefore, ODPHP used the community-based prevention marketing framework ${ }^{15}$ to develop a pilot test for implementation of the Move Your Way campaign. The pilot test took place from February to July 2019 in 2 communities (Las Vegas, NV, and Jackson, MS), where ODPHP also conducted formative research. The 6-month pilot test leveraged existing community health coalitions and used a combination of free community events; customized social media messages distributed through targeted ad campaigns; and customized posters and fact sheets distributed to schools, recreational facilities, community health centers, and other local organizations for display throughout the community. This multifaceted campaign approach was designed to ensure that community members in pilot test locations were exposed to the campaign through one or more of the preferred sources for information identified in this research.

\section{Emphasize Representation Through Inclusion and Diversity}

Participants had strong positive responses to images and messages that reflected both diverse activities and diverse individuals engaged in activities. Participants appreciated inclusive imagery and messages that reflected a range of ages, body types, and abilities, and strongly preferred images that showed more than one person engaged in an activity, which they associated with community and family. In prototype iconography, participants also strongly preferred generic figures (eg, "walk sign" figures) with no identifiable gender or race over more realistic figures. As such, the overall brand for the Move Your Way campaign uses generic figures (see Figure 1) —often engaged in group activities_-which represent a variety of ages, body types, and abilities. Targeted materials for specific groups (eg, older adults, children, parents, and health professionals) also include photographs that are representative of that particular group and inclusive of different ethnicities and abilities. Further, the campaign provides specific messages about short-term health outcomes (eg, better sleep and mood) and disease management benefits (eg, blood pressure control and diabetes management) from physical activity because participants 


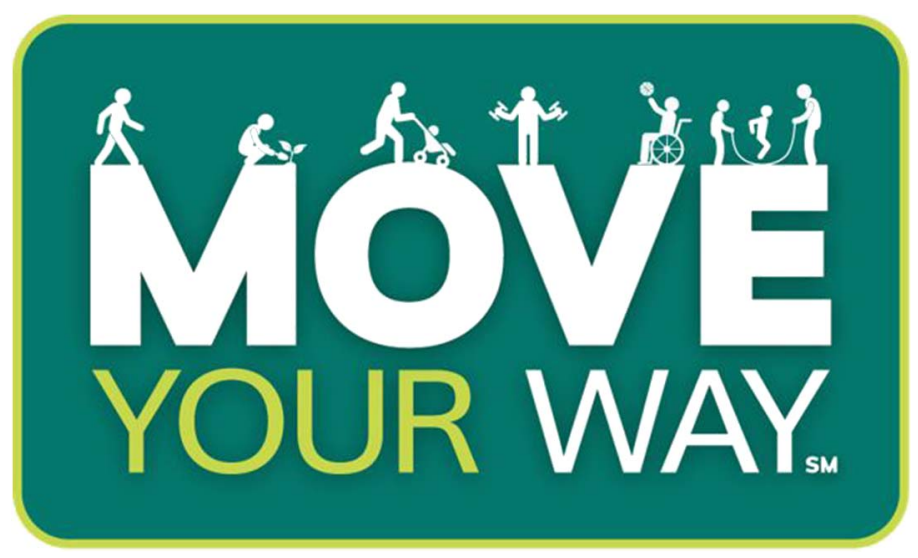

Figure 1 - Move Your Way graphic.

favored these types of messages over more generic messages (eg, "physical activity is good for you").

\section{Customize Physical Activity Recommendations to Make Them More Achievable}

Participants disliked "one-size-fits-all" recommendations for physical activity and had a strong preference for messages that broke up the recommendation of 150 minutes per week of moderateintensity aerobic activity into smaller, more realistic goals. Participants also expressed a preference for information about activities they could easily fit into their routines and how to do so. To this end, ODPHP created an interactive weekly activity planner that allows adults to build a customized plan based on their preferences and health goals and see their progress toward meeting the recommendations in the guidelines. With the planner, users can break up 150 minutes into manageable chunks and choose activities they can do in a variety of settings. The planner emphasizes that users can meet the recommendations in a variety of ways in the times and places that work for them. ODPHP also created an interactive tool for parents to assess whether their school-age children are meeting the guidelines. This tool has customizable settings that correspond with opportunities for children to get physical activity throughout the school day.

\section{Limitations}

The research activities summarized in this manuscript did not use representative samples, and results are not meant to be generalized to all physical activity contemplators, parents, children, teens, or the general population. Although both quantitative and qualitative data were collected for the adult and parent groups, no quantitative data were collected for children and teens.

For the survey, because data were collected from people who are in the contemplation stage and living in one of the 4 geographic areas, the eligible respondent pool from the Qualtrics panel was limited, and the sample was not as demographically diverse as would have been ideal. For example, participants in this sample were required to access the Internet to complete this survey, so they are likely to be more computer and web literate than those who do not have Internet access. Among Internet users, people with lower incomes and lower education levels tend to be underrepresented. ${ }^{16}$ However, the focus group samples were more demographically diverse-across the 3 groups, an average of 58\% were nonwhite, compared with the survey's $26 \%$ nonwhite participants. Likewise, focus group participants represented lower income categoriesacross the 3 groups, an average of 55\% reported a household income less than $\$ 50,000$, compared with $39 \%$ for survey participants.

\section{Implications for Practice}

ODPHP completed the research summarized in this article to inform the Move Your Way campaign, which was developed to promote the recommendations from the second edition of the Physical Activity Guidelines for Americans. Specifically, ODPHP used this research to inform Move Your Way campaign messages, products, and implementation strategies by applying the themes summarized above across a suite of resources available on health. gov. Community organizations, national nonprofits, health care facilities, local and state public health departments, and others can use these materials as they are, or integrate them into existing physical activity and health promotion activities. Further, those interested in promoting physical activity can use these findings to integrate the preferences of physical activity contemplators, parents, teens, and children into new communication campaigns.

\section{Conclusion}

The mixed-methods approach used for this study uncovered several findings that were consistent across multiple research activities. This consistency gave ODPHP confidence to use the findings to inform the implementation strategy and products for the Move Your Way campaign. For example, campaign iconography and messages emphasized inclusion and diversity, and campaign resources offered tips and tools for customizing physical activity recommendations. Further, based on this research, ODPHP used a unique implementation strategy adapted from the communitybased prevention marketing framework ${ }^{14}$ to leverage social and community connections for pilot tests in 2 communities. ODPHP intends to complete an evaluation of the Move Your Way campaign pilot tests that will help determine whether campaign products and implementation strategies informed by target audiences' self-reported physical activity message preferences and information-seeking preferences are effective at encouraging Americans to follow the Physical Activity Guidelines for Americans.

\section{Acknowledgments}

The authors thank the study participants, whose willingness to take the survey and participate in focus groups made this study possible. We are grateful to Alison Vaux-Bjerke (ODPHP) and Corinne Berry, Sean Arayasirikul, Morgan Griffin, and Janel Schuh (CommunicateHealth, Inc), who provided technical assistance, comments, and suggestions throughout the course of the study. The authors would also like to thank Blythe Miller, Laura Willwerth, and Andrea Mongler (CommunicateHealth, Inc) for their writing assistance. This work was supported by the U.S. Department of Health and Human Services.

\section{References}

1. U.S. Department of Health and Human Services. Physical Activity Guidelines for Americans: 2nd Edition. Washington, DC: U.S. Department of Health and Human Services; 2018. https://health. gov/paguidelines/second-edition/. Accessed May 20, 2019. 
2. Centers for Disease Control and Prevention. National Center for Health Statistics. National Health Interview Survey. https://www.cdc. gov/nchs/nhis/index.htm

3. 2018 Physical Activity Guidelines Advisory Committee. Scientific report. 2018. https://health.gov/paguidelines/second-edition/report. Accessed June 5, 2019.

4. The Community Guide. Health communication and social marketing: campaigns that include mass media and health-related product distribution. August 22, 2018. https://www.thecommunityguide.org/ findings/health-communication-and-social-marketing-campaigns-includemass-media-and-health-related. Accessed January 17, 2019.

5. Prochaska JO. Transtheoretical model of behavior change. In: Gellman MD, Turner JR, eds. Encyclopedia of Behavioral Medicine. New York, NY: Springer; 2013:1997-2000.

6. Cornacchione J, Smith SW. The effects of message framing within the stages of change on smoking cessation intentions and behaviors. Health Commun. 2012;27(6):612-622. PubMed ID: 22292861 doi:10.1080/10410236.2011.619252

7. Noar SM, Crosby R, Benac C, Snow G, Troutman A. Application of the attitude-social influence-efficacy model to condom use among African-American STD clinic patients: implications for tailored health communication. AIDS Behav. 2011;15(5):1045-1057. PubMed ID: 19685182 doi:10.1007/s10461-009-9599-x

8. Weinberg DS, Keenan E, Ruth K, Devarajan K, Rodoletz M, Bieber E. A randomized comparison of print and web communication on colorectal cancer screening. JAMA Intern Med. 2013;173(2):122129. PubMed ID: 23128366 doi:10.1001/2013.jamainternmed.1017

9. Marshall SJ, Biddle SJ. The transtheoretical model of behavior change: a meta-analysis of applications to physical activity and exercise. Ann Behav Med. 2001;23(4):229-246. PubMed ID: 11761340 doi:10.1207/S15324796ABM2304_2

10. Cleland V, Timperio A, Salmon J, Hume C, Telford A, Crawford D. A longitudinal study of the family physical activity environment and physical activity among youth. Am J Health Promot. 2011; 25(3):159-167. PubMed ID: 21192744 doi:10.4278/ajhp.090303QUAN-93

11. Gebel K, Bauman AE, Reger-Nash B, Leyden KM. Does the environment moderate the impact of a mass media campaign to promote walking? Am J Health Promot. 2011;26(1):45-48. PubMed ID: 21879942 doi:10.4278/ajhp.081104-ARB-269

12. Piercy KL, Bevington F, Vaux-Bjerke A, Williams Hilfiker S, Arayasirikul S, Barnett EY. Understanding contemplators' knowledge and awareness of the Physical Activity Guidelines. J Phys Act Health. 2020;17(4):404-411. doi:10.1123/jpah.2019-0393

13. Centers for Disease Control and Prevention. 2014 state indicator report on physical activity. July 2014. https://www.cdc.gov/ physicalactivity/downloads/pa_state_indicator_report_2014.pdf. Accessed May 20, 2019.

14. U.S. Department of Health and Human Services. OASH regional offices. October 19, 2016. https://www.hhs.gov/ash/about-ash/ regional-offices/index.html. Accessed April 8, 2019.

15. Bryant CA, Brown KR, McDermott RJ, et al. Community-based prevention marketing: organizing a community for health behavior intervention. Health Promot Pract. 2007;8(2):154-163. PubMed ID: 16923844 doi: $10.1177 / 1524839906290089$

16. Pew Research Center. Collecting survey data. 2020. https://www. pewresearch.org/methods/u-s-survey-research/collecting-survey-data/ \#internet-surveys. Accessed January 28, 2020. 